\title{
ALGEBRAIC PROPERTIES OF TRUNCATED TOEPLITZ OPERATORS
}

\author{
DONALD SARASON
}

Abstract. Compressions of Toeplitz operators to coinvariant subspaces of $H^{2}$ are studied. Several characerizations of such operators are obtained; in particular, those of rank one are described. The paper is partly expository. Open questions are raised.

Mathematics subject classification (2000): 47B35, 47B32.

\section{REFERENCES}

[1] P. R. Ahern and D. N. Clark, Radial limits and invariant subspaces, Amer. J. Math. 92 (1970), 332-342; MR0262511 (41\#7117).

[2] P. R. AHERn AND D. N. ClaRK, Radial $n$th derivatives of Blaschke products, Math. Scand. 28 (1971), 189-201; MR0318495 (47\#7042).

[3] A. B. AleKSANDROv, Multiplicity of boundary values of inner functions, Izv. Akad. Nauk Armyan. SSR Ser. Mat. 22 (1987), no. 5, 490-503, 515; MR931885 (89e:30058).

[4] A. B. AleKSANDROV, On the existence of angular boundary values of pseudocontinuable functions, Zap. Nauchn, Sem. S.-Peterburg. Otdel. Mat. Inst. Steklov (POMI) 222 (1995), Issled. po Linein. Oper. i Teor. Funktsii. 23, 5-17, 307; translation in J. Math. Sci. (New York) 87 (1997), no. 5, 3781-3787; MR135992 (97a:30046).

[5] A. B. ALEKSANDROV, Isometric embeddings of co-invariant subspaces of the shift operator, Zap. Nauchn. Sem. S.-Peterburg. Odtel. Mat. Inst. Steklov (POMI) 232 (1996), Issled. po Linein. Oper. i Teor. Funktsii. 24, 5-15, 213; translation in J. Math. Sci. (New York) 92 (1998), no. 1, 3543-3549; MR1464420 (98k:30050).

[6] J. A. BAll AND A. Lubin, On a class of contractive perturbations of restricted shifts, Pacific J. Math. 63 (1976), no. 2, 309-323; MR0417824 (54\#5872).

[7] H. BerCovicI, Operator Theory and Arithmetic in $H^{\infty}$, Mathematical Surveys and Monographs, 26, American Mathematical Society, Providence, RI, 1988; MR954383 (90e:47001).

[8] A. BRown And P. R. Halmos, Algebraic properties of Toeplitz operators, J. Reine Angew. Math. 213 (1963-1964), 89-102; MR0160136 (28\#3350).

[9] J. A. Cima, A. L. Matheson And W. T. Ross, The Cauchy Transform, Mathematical Surveys and Monographs, 125, American Mathematical Society, Providence, RI, 2006; MR2215991 (2006m:30003).

[10] D. N. ClaRK, One dimensional perturbations of restricted shifts, J. Analyse Math. 25 (1972), 169-191; MR0301534 (46\#692).

[11] R. B. CROFOOT, Multipliers between invariant subspaces of the backward shift, Pacific J. Math. 166 (1994), no. 2, 225-246; MR1313454 (95k:47009).

[12] S. R. GARCIA AND M. PUTINAR, Complex symmetric operators and applications, Trans. Amer. Math. Soc. 358 (2006), no. 3, 1285-1315; MR2187654 (2006j:47036).

[13] N. K. NIKOL'SKIĬ, Treatise on the Shift Operator, Grundlehren der Mathematischen Wissenschaften, 273, Springer-Verlag, Berlin, 1986; MR827223 (87i:47042).

[14] A. G. POltoratsKi, Boundary behavior of pseudocontinuable functions, Algebra i Analiz 5 (1993), no. 2, 189-210; translation in St. Petersburg Math. J. 5 (1994), no. 2, 389-406; MR1223178 (94k:30090). 
[15] D. SARASON, Generalized interpolation in $H^{\infty}$, Trans. Amer. Math. Soc. 127 (1967), 179-203; MR0208383 (34\#8193).

[16] D. Sarason, Sub-Hardy Hilbert Spaces in the Unit Disk, John Wiley \& Sons, Inc., New York, 1994; MR1289670 (96k:46039).

[17] B. SZ.-NAGY AND C. FoIAŞ, Harmonic Analysis of Operators on Hilbert Space, North-Holland Publishing Co., Amsterdam-London; American Elsevier Publishing Co., Inc., New York; Akadémiai Kiadó, Budapest, 1970; MR0275190 (37\#778). 